\title{
Using a multilocus phylogeny to test morphology-based classifications of Polystichum (Dryopteridaceae), one of the largest fern genera
}

Timothée Le Péchon ${ }^{1,2}$, Hai He ${ }^{3}$, Liang Zhang ${ }^{1}$, Xin-Mao Zhou ${ }^{1,4}$, Xin-Fen Gao ${ }^{1}$ and Li-Bing Zhang ${ }^{5^{*}}$

\begin{abstract}
Background: Polystichum (Dryopteridaceae) is probably the third largest fern genus in the world and contains ca. 500 species. Species of Polystichum occur on all continents except Antarctica, but its highest diversity is found in East Asia, especially Southwest China and adjacent regions. Previous studies typically had sparse taxon sampling and used limited DNA sequence data. Consequently, the majority of morphological hypotheses/classifications have never been tested using molecular data.

Results: In this study, DNA sequences of five plastid loci of 177 accessions representing ca. 140 species of Polystichum and 13 species of the closely related genera were used to infer a phylogeny using maximum likelihood, Bayesian inference, and maximum parsimony. Our analyses show that (1) Polystichum is monophyletic, this being supported by not only molecular data but also morphological features and distribution information; (2) Polystichum is resolved into two strongly supported monophyletic clades, corresponding to the two subgenera, $P$. subg. Polystichum and P. subg. Haplopolystichum; (3) Accessions of $P$. subg. Polystichum are resolved into three major clades: clade K (P. sect. Xiphophyllum), clade L (P. sect. Polystichum), and the HYMASO superclade dominated by accessions of $P$. sect. Hypopeltis, $P$. sect. Macropolystichum, and $P$. sect. Sorolepidium, while those of $P$. subg. Haplopolystichum are resolved into eight major clades; and (4) The monophyly of the Afra clade (weakly supported), the Australasian clade (weakly supported), and the North American clade (strongly supported) is confirmed.

Conclusions: Of the 23 sections of Polystichum recognized in a recent classification of the genus, four (P. sect. Hypopeltis, P. sect. Neopolystichum, P. sect. Sorolepidium, P. sect. Sphaenopolystichum) are resolved as non-monophyletic, 16 are recovered as monophyletic, and three are monospecific. Of the 16 monophyletic sections, two (P. sect. Adenolepia, $P$. sect. Cyrtogonellum) are weakly supported and 14 are strongly supported as monophyletic. The relationships of 11 sections (five in P. subg. Haplopolystichum; six in P. subg. Polystichum) are well resolved.
\end{abstract}

Keywords: Cyrtomium, Dryopteridaceae, Fern phylogeny, HYMASO superclade, HYSUFI clade, MCSCHMANS clade, Phanerophlebia, Polystichum

\footnotetext{
* Correspondence: Libing.Zhang@mobot.org

${ }^{5}$ Missouri Botanical Garden, P.O. Box 299, St. Louis, MO 63166-0299, USA

Full list of author information is available at the end of the article
} 


\section{Background}

As one of the most species-rich fern genera, Polystichum Roth (Dryopteridaceae) is almost a cosmopolitan genus naturally distributed on every continent except Antarctica. Estimates of the number of species in the genus worldwide have ranged from at least 200 [1], to slightly more than 225 [2], ca. 300 [3, 4] to ca. 380 [5]. Our recent explorations in species-rich areas such as southern China and northern and central Vietnam have demonstrated that there are actually far more species in the genus than had been thought. Besides, the application of molecular phylogenetics in the study of Polystichum has revealed a number of cryptic or semi-cryptic species of Polystichum previously unknown to science (e.g., [6-19]). Consequently, in its most recent circumscription (i.e., sensu $[18,20])$, Polystichum constitutes likely the third largest fern genus in the world with ca. 500 species [18], just smaller than Asplenium L. (ca. 660 spp. [21]; Aspleniaceae) and Elaphoglossum Schott ex J. Smith (ca. 600 spp. [22]; Dryopteridaceae). Species of Polystichum commonly occur in temperate and subtropical regions, in lowlands and montane to alpine areas, and are most diverse in the Northern Hemisphere, especially in southwestern and southern China, the Himalaya (ca. 50 spp., [2]), Japan (32 spp., [23]), and Vietnam (ca. 40 spp.). The Old World taxa represent ca. $80 \%$ of the species diversity in the genus. A rich diversity of Polystichum is also found in the mountains of tropical Americas (e.g., Central America: 18 spp.; Bolivia: 21 spp., [24]; Costa Rica: 12 spp., [25]; Cuba: ca. 17 spp., C. Sánchez, pers. comm.; Mexico: 17 spp., [26]; West Indies: 31 spp., [27]). About 15 species of Polystichum are distributed in North America and north of Mexico [28], 16 in mainland Africa [29], eight in Madagascar and the Mascarene Islands [30], three in Macronesia [31], four in Europe [32], 12 in Australasia [33, 34] and a few in New Guinea and the Pacific islands.

A morphology-based infrageneric classification of a group is basically phylogenetic hypotheses based on morphology. An infrageneric treatment of a genus is important for floristic and monographic studies and this is particularly true for a large genus like Polystichum [18]. Although infrageneric classifications of Polystichum go back at least to Keyserling [35] who established $P$. sect. Parapolystichum Keyserling (= Parapolystichum (Keyserl.) Ching), the first relatively comprehensive attempt at subdividing the genus in a natural way was conducted by Tagawa [36]. Based on morphological characters such as pinnation, the aspect of scales and sori, Tagawa [36] divided the species of Korea, Japan, and Taiwan into eight sections: $P$. sect. Achroloma Tagawa, P. sect. Crucifilix Tagawa, P. sect. Cyrtomiopsis Tagawa, "P. sect. Eupolystichum" Diels (=P. sect. Polystichum), P. sect. Haplopolystichum, P. sect. Mastigopteris Tagawa, P. sect. Metapolystichum Tagawa, and $P$. sect. Sorolepidium (Christ) Tagawa (Table 1).
In the study of the species of Polystichum of Japan, Ryukyu, and Taiwan, Daigobo [37] recognized Tagawa's [36] eight sections and proposed an additional eight ones mainly based on the morphology of microscales on abaxial leaf surfaces: $P$. sect. Adenolepia Daigobo, $P$. sect. Lasiopolystichum Daigobo, P. sect. Macropolystichum Daigobo, P. sect. Micropolystichum Daigobo, P. sect. Prionolepia Daigobo, $P$. sect. Scleropolystichum Daigobo, $P$. sect. Stenopolystichum Daigobo, and P. sect. Xiphopolystichum Daigobo (Table 1). Notably, P. sect. Scleropolystichum is a homotypic synonym of $P$. sect. Hypopeltis with $P$. aculeatum as its type [18].

Fraser-Jerkins [2, 38] classified the 45 species of the Indian Subcontinent into seven sections: $P$. sect. Duropolystichum Fraser-Jenkins, P. sect. Hypopeltis (Michx.) T.Moore, P. sect. Macropolystichum, P. sect. Metapolystichum, $P$. sect. Micropolystichum, $P$. sect. Polystichum, and P. sect. Sorolepidium (Table 1).

In revising the African species of Polystichum, Roux [39] classified the 24 species he recognized into nine sections including $P$. sect. Lasiopolystichum, $P$. sect. Metapolystichum, P. sect. Xiphopolystichum, and other six sections (nom. nud.) he proposed in his Ph.D. dissertation. Later when he published his work [29] he did not describe these six sections officially and recognized only 16 species and one hybrid for Africa. An extensive study of subdividing Polystichum was conducted by Kung et al. [4] where the then recognized 168 species of Polystichum in China were accommodated in 13 sections. Four of Tagawa's [36] eight sections and six of Daigobo's [37] 16 sections were adopted, albeit often with dramatically different circumscriptions. Two additional sections were introduced: P. sect. Neopolystichum Ching ex Li Bing Zhang \& H.S.Kung and P. sect. Sphaenopolystichum Ching ex W.M.Zhu \& Z.R.He (Table 1).

The most recent and comprehensive subdivision of Polystichum was performed by Zhang and Barrington [18] who arranged the 208 species recognized for Flora of China in two subgenera: P. subg. Polystichum and $P$. subg. Haplopolystichum (Tagawa) Li Bing Zhang, and the former further into 14 sections while the latter into nine sections (Table 1). Nine of the 23 sections were newly proposed and most of the existing sections were circumscribed differently in comparison with their earlier delimitations by Tagawa [36], Daigobo [37], Fraser-Jerkins [2, 38] and Kung et al. [4].

In the era of molecular phylogenetics, although substantial progress in understanding the phylogeny of Polystichum has been achieved using plastid rbcL, rps4trnS, and trnL-F data $[1,11,13,15,40-45]$, the relationships among sections, species, and previously recognized genera, Cyrtogonellum and Cyrtomidictyum, as well as Cyrtomium subser. Balansana, have not yet been resolved and the majority of the Asian species not 
Table 1 Infrageneric classifications of Polystichum

\begin{tabular}{|c|c|c|c|c|}
\hline Tagawa [36] & Daigobo [37] & Fraser-Jenkins $[2,38]$ & Kung et al. [4] & Zhang and Barrington [18] \\
\hline & & & & P. subg. Polystichum \\
\hline P. sect. Achroloma & P. sect. Achroloma & - & - & P. sect. Achroloma (2/2) \\
\hline P. sect. Polystichum & P. sect. Polystichum & P. sect. Polystichum & P. sect. Polystichum & P. sect. Polystichum (9/30) \\
\hline P. sect. Sorolepidium & P. sect. Sorolepidium & P. sect. Sorolepidium & - & P. sect. Sorolepidium (7/16) \\
\hline P. sect. Macropolystichum & P. sect. Macropolystichum & P. sect. Macropolystichum & P. sect. Macropolystichum & P. sect. Macropolystichum (8/17) \\
\hline P. sect. Micropolystichum & P. sect. Micropolystichum & P. sect. Micropolystichum & P. sect. Micropolystichum & P. sect. Micropolystichum (2/6) \\
\hline - & P. sect. Hypopeltis & P. sect. Hypopeltis & P. sect. Hypopeltis & P. sect. Hypopeltis (46/70) \\
\hline- & P. sect. Stenopolystichum & - & P. sect. Stenopolystichum & P. sect. Stenopolystichum (2/3) \\
\hline- & P. sect. Xiphopolystichum & - & P. sect. Xiphopolystichum & P. sect. Xiphopolystichum (14/34) \\
\hline- & - & - & P. sect. Neopolystichum & P. sect. Neopolystichum (2/4) \\
\hline- & - & - & - & P. sect. Fimbriata (1/1) \\
\hline- & - & - & - & P. sect. Hecatoptera (1/1) \\
\hline- & - & - & - & P. sect. Crinigera (1/1) \\
\hline- & - & - & - & P. sect. Subfimbriata (1/1) \\
\hline \multirow[t]{2}{*}{-} & - & - & - & P. sect. Chingiarum (1/1) \\
\hline & & & & P. subg. Haplopolystichum \\
\hline P. sect. Cyrtomiopsis & P. sect. Cyrtomiopsis & - & - & P. sect. Cyrtomiopsis (2/4) \\
\hline P. sect. Crucifix & P. sect. Crucifix & - & P. sect. Crucifix & P. sect. Crucifix (3/4) \\
\hline P. sect. Haplopolystichum & P. sect. Haplopolystichum & - & P. sect. Haplopolystichum & P. sect. Haplopolystichum (6/54) \\
\hline P. sect. Mastigopteris & P. sect. Mastigopteris & - & P. sect. Mastigopteris & P. sect. Mastigopteris (1/2) \\
\hline P. sect. Metapolystichum & P. sect. Metapolystichum & P. sect. Metapolystichum & P. sect. Metapolystichum & \\
\hline - & P. sect. Adenolepia & - & - & P. sect. Adenolepia (4/6) \\
\hline- & P. sect. Lasiopolystichum & - & P. sect. Lasiopolystichum & - \\
\hline- & P. sect. Prionolepia & - & - & - \\
\hline - & - & P. sect. Duropolystichum & P. sect. Scleropolystichum & - \\
\hline- & P. sect. Sphaenopolystichum & - & P. sect. Sphaenopolystichum & P. sect. Sphaenopolystichum (5/12) \\
\hline - & - & - & - & P. sect. Basigemmifera (3/5) \\
\hline- & - & - & - & P. sect. Cyrtogonellum (3/5) \\
\hline- & - & - & - & P. sect. Platylepia (3/4) \\
\hline
\end{tabular}

Numbers in the brackets in the last column indicate numbers of species included in our study and the total numbers of species known in the sections

included in any molecular analyses. So far no monophyletic supraspecific taxa except Cyrtomidictyum $(=P$. sect. Cyrtomiopsis Tagawa) have been recovered using molecular data. Almost all morphological hypotheses about the relationships within Polystichum, especially in terms of subdivisions of the genus, have largely remained speculative.

The objectives of this study included: (1) to test the monophyly of Polystichum using the largest taxon and character sampling so far; (2) to resolve the major relationships within Polystichum worldwide with focus on the Old World taxa which represent ca. $80 \%$ of the species diversity in the genus; (3) to evaluate the monophyly of the supraspecific taxa recognized in the most recent classification and to test other previous morphologybased hypotheses of relationships within Polystichum.

\section{Results}

This study generated 334 new sequences (Additional file 1). The dataset characteristics and tree statistics for the analyses are presented in Table 2. Comparisons of tree topologies from MPJK analyses of the individual markers did not identify any well-supported conflicts (MPJK $\geq 70 \%$; [46-48]). Thus, the five datasets were concatenated. The topology of the ML tree based on the concatenated dataset (Fig. 1) is mostly identical to those based on each individual marker, but with generally increased support values.

Polystichum is weakly supported (MLBS: 57 \%; MPJK: $58 \%$; BIPP: < 0.5) as monophyletic and sister to a clade containing Cyrtomium and Phanerophlebia (Fig. 1a). Within Polystichum, the two subgenera, P. subg. Polystichum (MLBS: 99 \%; MPJK: 99 \%; BIPP: 1.00) and P. subg. Haplopolystichum (MLBS: 100 \%; MPJK: 99 \%; BIPP: 1.00), 
Table 2 Data matrices and best-fitting models for separate ( $r b c L$, psbA-trnH, rps4-trnS, trnL, trnL-F, and $\operatorname{trn} L$ and $\operatorname{trn} L-F$ ) plastid datasets in this study

\begin{tabular}{|c|c|c|c|c|c|}
\hline & $\begin{array}{l}\text { psbA- } \\
\text { trnH }\end{array}$ & $r b c L$ & $\begin{array}{l}\operatorname{trn} L- \\
\operatorname{trn} L-F\end{array}$ & $\begin{array}{l}\text { trns- } \\
\text { rps4 }\end{array}$ & Combined \\
\hline Number of accessions & 126 & 143 & 141 & 121 & 177 \\
\hline $\begin{array}{l}\text { Total aligned } \\
\text { characters }\end{array}$ & 475 & 1227 & 1041 & 478 & 3218 \\
\hline$\%$ missing data & $17.6 \%$ & $1.8 \%$ & $31.1 \%$ & $19.6 \%$ & $35,6 \%$ \\
\hline $\begin{array}{l}\text { Number of new } \\
\text { sequences }\end{array}$ & 90 & 65 & 94 & 85 & 334 \\
\hline \# PI chars. & 76 & 198 & 299 & 178 & 743 \\
\hline $\begin{array}{l}\text { AlC-criterium } \\
\text { model }\end{array}$ & $\mathrm{GTR}+\mathrm{G}$ & $\begin{array}{l}\text { GTR+I } \\
+G\end{array}$ & $\begin{array}{l}\text { GTR+l } \\
+G\end{array}$ & $\begin{array}{l}\text { GTR+l } \\
+G\end{array}$ & $\mathrm{GTR}+\mathrm{I}+\mathrm{G}$ \\
\hline
\end{tabular}

$P I$ parsimony-informative

are strongly supported as monophyletic. Within $P$. subg. Haplopolystichum, the 43 accessions of the 34 species are resolved into seven well-supported clades (Fig. 1a: clades A-D, F, G+H, J; MLBS $\geq 96$ \%; MPJK: $\geq 98$ \%; BIPP: 1.00) and one weakly supported clade (Fig. 1a: clade E; MLBS:
51 \%; MP: unresolved; BIPP: 0.94). Within P. subg. Polystichum, the 121 accessions of the 106 species are resolved into three well-supported clades: clade K (MLBS: $98 \%$; MPJK: 100 \%; BIPP: 1.00), clade L (MLBS: 85 \%; MPJK: 78 \%; BIPP: 0.64), and the HYMASO superclade (Hypopeltis-Macropolystichum-Sorolepidium dominant superclade; MLBS: 98 \%; MPJK: 84 \%; BIPP: 0.7), and the HYMASO superclade further into a number of clades including the MCSCHMANS (Macropolystichum-Chingiarum-Sorolepidium-Crinigera-Hecatoptera-Micropolystichum-AchrolomaNeopolystichum-Stenopolystichum) clade, the HYSUFI (Hypopeltis-Subfimbriata-Fimbriata) clade, the Afra clade, the Australasian clade, and the North American clade (Fig. 1b). The HYSUFI clade is weakly supported as monophyletic and comprises clades V, W, and X1-X3, P. discretum (Don) J.Sm., P. retrosopaleaceum (Kodama) Tagawa, and $P$. weimingii Li Bing Zhang \& H.He, while the MCSCHMANS clade is strongly supported as monophyletic (Fig. 1b; MLBS: 78 \%; MPJK: 78 \%; BIPP: 1.0) and contains clades $\mathrm{M}-\mathrm{U}$, P. bakerianum (Atkins.) Diels, and an undescribed species from Sichuan, China.
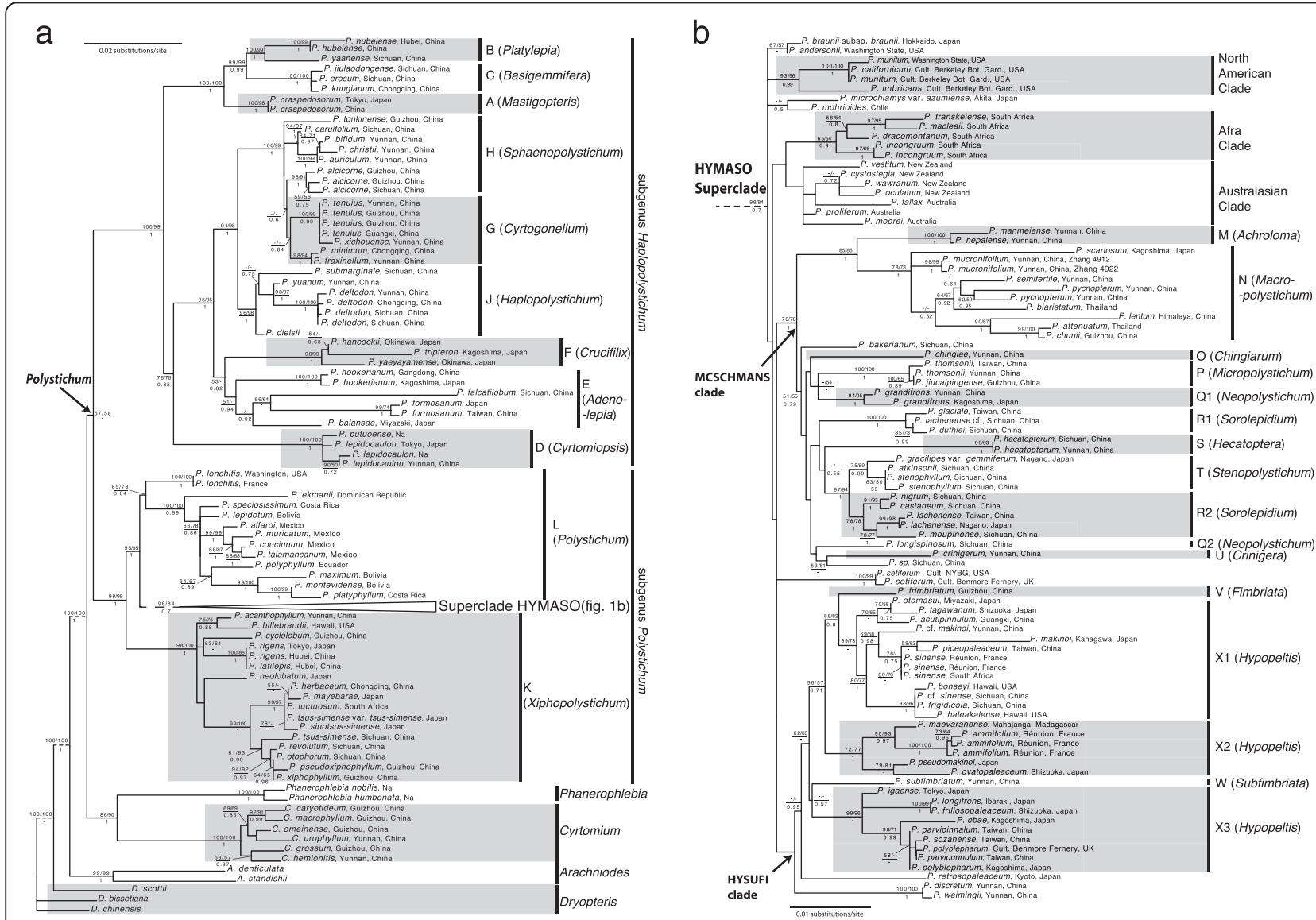

Fig. 1 Simultaneous-analysis maximum likelihood tree of Polystichum based on five chloroplast markers (psbA-trnH intergenic spacer, rbcL gene, rps4-trnS intergenic spacer, trnL intron, and trnL-F intergenic spacer) of 177 accessions representing ca. 140 species of Polystichum and 13 species of the closely related four genera as outgroups. Maximum parsimony jackknife (MPJK) values/maximum likelihood bootstrap (MLBS) values/ Bayesian inference posterior probability (BIPP) values are along the branches. Dashed branches indicate the disproportional branch lengths 


\section{Discussion}

\section{Monophyly of Polystichum and its relationships with Cyrtomium and Phanerophlebia}

While the monophyly of polystichoid ferns (i.e., Cyrtomium, Phanerophlebia and Polystichum) has been highly supported in previous studies [1, 44], the relationships among these three genera remain ambiguous. With the largest sampling so far (about three times as large as the previous largest worldwide sampling by Driscoll and Barrington [44]), our study resolved Polystichum as monophyletic but only with weak support (MLBS: $57 \%$; MPJK: $58 \%$; BIPP: < 0.50). Although earlier studies [1, 49] using a limited molecular sampling (only $r b c L$ sequences) found Polystichum (sensu $[18,20]$ ) as paraphyletic in relation to Cyrtomium (weak support), the monophyly of Polystichum is further supported by several morphological features (i.e., lamina 1-3-pinnate, apex pinnatifid, without a clear apical pinna; venation mostly free, rarely anastomosing to form 1 or 2 rows of areoles). Our result is also consistent with some more recent studies based on multi-locus datasets $[42,44,50]$.

The sister relationship between Cyrtomium and Phanerophlebia is highly supported by our phylogenetic reconstructions (MLBS: 86 \%; MPJK: 90 \%; BIPP: 1.00, Fig. 1a). As early as 1988 Yatskievych et al. already found that Cyrtomium and Phanerophlebia are convergent descendants from different progenitor groups based on chloroplast restriction site data [51]. However, a closer relationship of Polystichum with Cyrtomium than with Phanerophlebia was found by Li et al. [42] based on plastid trnL-F and rps4-trnS data and by Mc Keown et al. [50]. Our data do not support this resolution (Fig. 1).

Generally, the relationships among polystichoid ferns obtained here are in agreement with those found in most of the earlier phylogenetic studies but more studies are needed to fully resolve the relationships among these three genera.

\section{Relationships within Polystichum}

Within Polystichum, 164 accessions are resolved into two monophyletic clades corresponding to $P$. subg. Polystichum and P. subg. Haplopolystichum (Tagawa) Li Bing Zhang defined by [18], both with strong support. The sister relationship between these two subgenera agrees with the morphology and the findings with molecular data by Driscoll and Barrington [44] and Li et al. [42], but contrasts those by Little and Barrington [1] and Lu et al. [49] based on $r b c L$ data alone which resolved $P$. subg. Polystichum as sister to Cyrtomium, and them together as sister to $P$. subg. Haplopolystichum (also see above). The bulbil-bearing species are resolved in five clades (A, C, D, N, T), suggesting that bulbils evolved at least five times in Polystichum, twice in P. subg. Polystichum and three times in P. subg. Haplopolystichum.
I Polystichum subg. Haplopolystichum (Tagawa) Li Bing Zhang (Fig. 1a): Nine sections are recognized by Zhang and Barrington [18] in this subgenus. The monophyly of all but two sections is recovered and six sections are well supported as monophyletic. The relationships among all but four sections in the subgenus are well resolved.

1 Polystichum sect. Mastigopteris Tagawa (Fig. 1a: clade A). - Morphologically, this section is characterized by having entire indusia [18] and it contains only two species following Zhang and Barrington [18], a delimitation different from that of Kung et al. [4] who included P. erosum Ching \& Shing in this section as well. Two accessions representing only the type of the section, $P$. craspedosorum (Maxim.) Diels, were included in our study. Our results show that this section is strongly (MLBS: 100 \%; MPJK: 98 \%; BIPP: 1.00) supported as sister to a clade containing $P$. sect. Basigemmifera and $P$. sect. Platylepia, and these three sections together are sister to the rest of the subgenus. Our study also shows that $P$. sect. Mastigopteris sensu Kung et al. [4] is paraphyletic in relation to portion of $P$. sect. Basigemmifera and P. sect. Platylepia (Fig. 1a: clades B and C).

2 Polystichum sect. Platylepia Li Bing Zhang (Fig. 1a: clade B). - This section, characterized by having ovate to broadly lanceolate rachis scales and once-pinnate lamina [18], contains 3-4 species occurring in Southwest to central China. Three accessions representing three species of this section were included in our study. Our data resolved this section as monophyletic (MLBS: 100 \%; MPJK: 99 \%; BIPP: 1.00) and sister to $P$. sect. Basigemmifera. This resolution is not in conflict with what we found earlier based on plastid trnL-F data alone [10], which placed $P$. sect. Platylepia (represented by P. yaanense Liang Zhang \& Li Bing Zhang), P. sect. Basigemmifera, and $P$. sect. Mastigopteris in an unresolved trichotomy.

3 Polystichum sect. Basigemmifera (W.M.Chu \& Z.R.He) Li Bing Zhang (Fig. 1a: clade C). - This section has been accommodated in $P$. sect. Micropolystichum by Kung et al. [4] as P. ser. Basigemmifera W.M.Chu \& Z.R.He based on the small size of plants and pinna morphology of the members. However, the type of $P$. sect. Micropolystichum, the tetraploid sexual $P$. thomsonii (Hook.f.) Bedd., and its relatives lack bulbils on the rachis and are members of $P$. subg. Polystichum (see below), while members of $P$. sect. Basigemmifera have bulbils on the rachis and are members of $P$. subg. Haplopolystichum. 
This section contains about five species, four of which are endemic to Southwest to central China [18]. We included three species in this study including the sexual tetraploid P. erosum Ching \& K.S.Shing. Our data confirmed the monophyly of this section (MLBS: $100 \%$; MPJK: $100 \%$; BIPP: 1.00), consistent with our earlier findings based on more species and accessions sampled [10, 15]. Our data resolved this section as sister to $P$. sect. Platylepia (Fig. 1a: clade B).

4 Polystichum sect. Cyrtomiopsis Tagawa (Fig. 1a: clade D). - This section contains about four species and is characterized by prolonged rachis apex with bulbils and broad-type microscales [18]. This section was often recognized as a genus, i.e., Cyrtomidictyum Ching (e.g., [52, 53]). Our data resolved it as part of $P$. subg. Haplopolystichum, a result consistent with those in earlier studies [10, 15, 42, 44, 49, 53]. Our study further resolved this section as monophyletic (MLBS: 100 \%; MPJK: 100 \%; BIPP: 1.00) and sister (MLBS: $78 \%$; MPJK: 76 \%; BIPP: 0.85) to a clade containing $P$. sect. Adenolepia, $P$. sect. Crucifilix, $P$. sect. Cyrtogonellum, P. sect. Haplopolystichum, and $P$. sect. Sphaenopolystichum (all sections of the subgenus except $P$. sect. Basigemmifera, $P$. sect. Mastigopteris, and $P$. sect. Platylepia). This resolution is consistent with that found by Driscoll and Barrington ([44]; maximum parsimony bootstrap: $100 \%$; 7 species of the subgenus sampled) and that by Lu et al. ([49]; maximum parsimony bootstrap: $67 \%$; 12 species of the subgenus sampled but $P$. sect. Mastigopteris was not sampled), but inconsistent with that found by Li et al. [42] who resolved $P$. sect. Cyrtomiopsis (one species sampled) as sister to the rest of $P$. subg. Haplopolystichum (maximum parsimony bootstrap: $70 \%$ ) based on plastid trnL-F and rps4-trnS data. Occasionally, veinlets in species of this section can be anastomosing.

5 Polystichum sect. Adenolepia Daigobo (Fig. 1a: clade E). - This section in its new circumscription [18] contains about six species including four assigned to Cyrtomium in early classifications (e.g., [4]). We sampled four species in our study. Our analyses recovered the monophyly of the section but only with weak support in ML and MP analyses (MLBS: < 50 \%; MPJK: < 50 \%) but moderately support in BI analysis (BIPP: 0.94). Interestingly, the two former members of Cyrtomium, which have anastomosing venation $[P$. balansae Christ, $P$. hookerianum (C.Presl) C.Chr.], are paraphyletic in relation to two species with free venation, suggesting that the anastomosing venation in the section evolved at least twice or evolved once but reversed to free venation from anastomosing venation in the P. falcatilobum $+P$. formosanum clade. Polystichum sect. Adenolepia sensu Daigobo [37], which included P. obliquum (Don) T.Moore, a member of $P$. sect. Haplopolystichum, is apparently polyphyletic.

6 Polystichum sect. Crucifilix Tagawa (Fig. 1a: clade F). - This section contains only four species, three of which were included in our study. Our data confirmed the monophyly of this section (MLBS: 98 \%; MPJK: 99 \%; BIPP: 1.00) and resolved it as sister to $P$. sect. Adenolepia, but this resolution is only weakly supported (MLBS: 53 \%; MP: unresolved; BIPP: 0.82). The Japanese endemic $P$. yaeyamense (Makino) Makino is surprisingly resolved as a member of $P$. sect. Crucifilix. A close examination of herbarium material of $P$. yaeyamense shows that some individuals of this species have and some do not have bipinnate lamina base, similar to $P$. normale Ching ex P. S. Wang \& Li Bing Zhang [54], another member of this section [18].

7 Polystichum sect. Cyrtogonellum (Ching) Li Bing Zhang (Fig. 1a: clade G). - This section was often treated as a genus (e.g., [52]) but was recently considered as a section of Polystichum by Zhang and Barrington [18]. Liu et al. [53] recovered the monophyly of this section with high MLBS support (95\%). Our earlier trnL-F data alone resolved this section as paraphyletic in relation to P. subg. Haplopolystichum [9]. Our current study recovered the monophyly of the section but with low statistical support in ML and BI analyses (MLBS < 50 \%; BIPP: 0.84). Monophyly of $P$. sect. Cyrtogonellum is supported by morphology: species of this section have one row of sori on each side of midrib, pinnae symmetrical or nearly symmetrical at the base except $P$. minimum (Y.T.Hsieh) Li Bing Zhang. One species ( $P$. fraxinellum (Christ) Diels) and one hybrid $(P$. xrupestris P.S. Wang \& Li Bing Zhang) included in this section have anastomosing venation [18]. This, together with anastomosing venation in $P$. sect. Adenolepia (see above) and sometimes in $P$. sect. Cyrtomiopsis, reinforces that anastomosing venation in Polystichum evolved multiple times independently.

8 Polystichum sect. Sphaenopolystichum Ching ex W.M.Chu \& Z.R.He (Fig. 1a: "clade" H). - This section is the only one in the subgenus with pinnae finely dissected $[4,18]$ and contains about 
15 species. Lu et al. [49] recovered the monophyly of the section (MPBS: $98 \%$ ) but only two species were sampled. Liu et al. [53] sampled three species and recovered the monophyly of $P$. sect. Sphaenopolystichum but without any statistical support. Our data of eight accessions representing ca. eight species failed to recover the monophyly of the section in all three analyses; instead the eight accessions were resolved into three subclades: the P. alcicorne subclade containing ca. three species, the $P$. tonkinense subclade containing one species, and the $P$. auriculum subclade containing $P$. auriculum Ching, P. bifidum Ching, P. caruifolium (Baker) Diels, and P. christii Ching (Fig. 1a: clade H). In $\mathrm{BI}$ analysis, the $P$. alcicorne subclade is resolved as sister to $P$. sect. Cyrtogonellum with BIPP $=$ 0.60. P. sect. Sphaenopolystichum together with $P$. sect. Cyrtogonellum is strongly supported as monophyletic (MLBS: 100 \%; MPJK: 99 \%; BIPP: 1.00). One member of the section, $P$. wattii (Bedd.) C.Chr., has never been included in any molecular studies and might not belong to this section.

9 Polystichum sect. Haplopolystichum Tagawa (Fig. 1a: clade J). - In its recent circumscription (i.e., sensu Zhang and Barrington [18]), P. sect. Haplopolystichum, is different from its original delimitation by Tagawa [36]. The latter contained also $P$. sect. Adenolepia, $P$. sect. Hecatoptera, and $P$. sect. Stenopolystichum in our definition [18]. Our results show that $P$. sect. Haplopolystichum sensu Tagawa [36] is highly polyphyletic and taxa included in its original definition are resolved in two subgenera (see above and our Fig. 1a, b). This section in our definition [18] is estimated to contain about 200 species [18] and almost all species recently described from southern China and Vietnam belong to this section [6-11, 15, 16, 19, 55]. We included seven accessions representing four species. An ongoing project focusing on this section will include many more species. Our current study shows that this section is strongly supported as monophyletic (MLBS: 96 \%; MPJK: 98 \%; BIPP: 1.00) and is resolved as sister (MLBS: $94 \%$; MPJK: $99 \%$; BIPP: 1.00) to a clade containing $P$. sect. Cyrtogonellum and $P$. sect. Sphaenopolystichum.

II Polystichum subg. Polystichum: All accessions of this subgenus are resolved into three major clades: clade K (P. sect. Xiphophyllum; well supported), clade L (P. sect. Polystichum; moderately supported), and the HYMASO superclade (MLBS: 98 \%; MPJK: 84 \%; BIPP: 0.7). The HYMASO superclade represents ca. $30 \%$ of the species diversity in the genus and is morphologically diverse. It contains 11 of the 23 sections recognized by Zhang and Barrington [18] for the genus in China. Within the HYMASO superclade, the relationships are poorly resolved. Nevertheless, we recovered two major clades: the HYSUFI clade (weakly supported) and the MCSCHMANS clade (moderately supported). The former contains species of $P$. sect. Hypopeltis, $P$. sect. Fimbriata, and $P$. sect. Subfimbriata, while the latter contains species of nine sections recognized by Zhang and Barrington [18]. The bulbil-bearing species in the subgenus only appear in the MCSCHMANS clade. 10 Polystichum sect. Xiphopolystichum Daigobo (Fig. 1b: clade K). - Polystichum sect.

Xiphopolystichum is defined as a combination of $P$. sect. Xiphopolystichum sensu Kung et al. [4] and P. sect. Duropolystichum Fraser-Jenk. [18]. Fifteen out of ca. 34 species of the section were sampled in our study (the largest sampling so far). This clade, strongly supported as monophyletic (MLBS: 98 \%; MPJK: 100 \%; BIPP: 1.00), is resolved as sister to the rest of the subgenus with high support values (MLBS: 99 \%; MPJK: 99 \%; BIPP: 1.00). P. sect. Xiphopolystichum is also characterized by several morphological features such as the lamina stiff, leathery or nearly leathery, often shiny adaxially; the pinnae dentate and with hard spinules at apex and often also on margin; and the rachis scales linear and brown to blackish [18]. Our resolution is consistent with that found by Driscoll and Barrington [44] who sampled five species only. Within the section (clade K), $P$. sect. Xiphopolystichum sensu Kung et al. [4] strongly supported as monophyletic (MLBS: 99 \%; MPJK: 100 \%; BIPP: 1.00), while P. sect. Scleropolystichum (= P. sect. Duropolystichum) sensu Kung et al. [4] is paraphyletic in relation to $P$. sect. Xiphopolystichum sensu Kung et al. [4]. Morphologically, P. sect. Duropolystichum could well be monophyletic based on its open spines on the pinna margins and thicker leaves [4]. More molecular data might recover the monophyly of P. sect. Duropolystichum.

11 Polystichum sect. Polystichum (Fig. 1b: clade L). Ten accessions representing nine species of this section are resolved as the second earliest divergent lineage in the subgenus (MLBS: $85 \%$; MPJK: 78 \%; BIPP: 0.64), which is consistent with the findings by Driscoll and Barrington [44] who first discovered this clade. Species of this section occur in the circumboreal regions (P. lonchitis 
(L.) Roth, a diploid sexual species) and the New World tropics [18, 44]. McHenry and Barrington [45] further discovered that the exindusiate Andean Polystichum was sister to the Mexican Polystichum clade and they together were sister to the Mexican P. speciosissimum (Kunze) R.M.Tryon \& A.F.Tryon. Morphologically, this section is characterized by having lamina papery or leathery, 1-pinnate to bipinnate; pinna or pinnule spinulose or not spinulose on the margins; and sori indusiate or exindusiate [18, 45]. The currently defined $P$. sect. Polystichum sensu Driscoll and Barrington [44] and Zhang and Barrington [18] might need further division based on the results of McHenry and Barrington [45]. Polystichum sect. Polystichum sensu FraserJenkins [38] also included the tetraploid sexual $P$. acutidens Christ and four diploid sexuals $P$. atkinsonii Bedd., P. nepalense (Spr.) C.Chr., $P$. obliquum (D.Don) T.Moore, and P. stenophyllum Christ. Our study, together with previous studies (e.g., $[9,10]$ for the relationships of $P$. acutidens and $P$. obliquum), shows that $P$. sect. Polystichum sensu Fraser-Jenkins [38] is apparently polyphyletic as these members are resolved in three independent clades (Fig. 1a and b: clades J, L, T).

12 Polystichum sect. Achroloma Tagawa (Fig. 1b: clade M). - When Tagawa [36] established this section, he included only the type $P$. nepalense (Spr.) C.Chr. (a diploid sexual species). Daigobo [37] added $P$. falcatipinnum Hayata (= P.

manmeiense (Christ) Nakaike, tetraploid sexual) to this section. This delimitation was accepted by Zhang and Barrington [18] but rejected by Kung et al. [4] who included the two species in $P$. sect. Polystichum. Fraser-Jenkins [38] placed the latter species in $P$. sect. Hypopeltis. Our study is the first to sample both of the species in a molecular analysis. Two species formed a clade with strong support (MLBS: 100 \%; MPJK: 100 \%; BIPP: 1.00) in our analysis. This section is resolved as sister to the P. sect. Macropolystichum clade (MLBS: $85 \%$; MPJK: $85 \%$; BIPP: 1.0), consistent with the resolution found by Driscoll and Barrington [44]. These two sections share evergreen leaves which are shiny adaxially.

13 Polystichum sect. Macropolystichum Daigobo (Fig. 1b: clade N). - As defined by Zhang and Barrington [18], this section contains species with or without proliferous bulbils but all members are of relatively large habit and laminae that are dark green and shiny adaxially. Ten accessions representing about 8 out of ca. 17 species of this section are sampled in our study (the largest sampling so far). Our analyses recovered the monophyly of $P$. sect. Macropolystichum sensu Zhang and Barrington [18] with strong support (MLBS: 78 \%; MPJK: 73 \%; BIPP: 1.00). Polystichum sect. Macropolystichum sensu Daigobo [37] which includes P. kiusiuense Tagawa (= P. grandifrons C.Chr.; [56]) is apparently polyphyletic. The type of $P$. sect. Prionolepis Daigobo, the tetraploid sexual $P$. biaristatum (Blume) T.Moore, is resolved as a member of $P$. sect. Macropolystichum sensu Zhang and Barrington [18] suggesting that $P$. sect. Prionolepis is a heterotypic synonym of $P$. sect. Macropolystichum. The same species was treated as a member of $P$. sect. Neopolystichum by Zhang and Kung [57], but this is not supported by our data. P. mucronifolium, resolved as a member of $P$. sect. Macropolystichum in our study, was placed in P. sect. Metapolystichum Tagawa, a heterotypic synonym of $P$. sect. Hypopeltis [18], by Fraser-Jenkins [38].

14 Polystichum sect. Chingiarum Li Bing Zhang (Fig. 1b: clade O). - This monospecific section contains P. chingiae Ching [18] and our study is the first to include it in a molecular analysis. Our study resolved the species in the MCSCHMANS clade, but its relationships are not well resolved. The isolated phylogenetic position is consistent with its special morphology. Morphologically, this species has lamina 1-pinnate, pinnae not cartilaginous at margins, and sori in 2 or 3 rows on each side of midrib and abaxial on veinlets [18]. Such a combination of morphological features is unique within the genus.

15 Polystichum sect. Micropolystichum Tagawa (Fig. 1b: clade P). - This section contains only about six montane to alpine species [18]. We included three accessions representing two species. Our study resolved $P$. sect. Micropolystichum as a strongly supported clade (MLBS: 100 \%; MPJK: 100 \%; BIPP: 1.00) which is sister to P. grandifrons, but the sister relationship between those lineages is weakly supported statistically (MLBS: $<50 \%$; MPJK: $<50 \%$ ) and morphologically [18]. Fraser-Jenkins [38] also placed the diploid sexual Polystichum capillipes (Baker) Diels and P. wattii (Bedd.) C.Chr. in P. sect. Micropolystichum. Neither of the species were sampled in our current study, but our earlier study [10] resolved the former species in P. sect. Basigemmifera (Fig. 1a: clade C).

16 Polystichum sect. Neopolystichum Ching ex Li Bing Zhang \& H.S.Kung (Fig. 1b: clade Q). When Zhang and Kung [57] described this 
section, seven species were included. Zhang and Barrington [18] excluded P. biaristatum (Blume) T.Moore, P. mucronifolium (Blume) C.Presl, and P. parvifoliolatum W.M.Chu from the section sensu Zhang and Kung [57] but recognition of this section was tentative pending more evidence. We included three accessions representing two species in this study: P. grandifrons and $P$. longispinosum Ching ex Li Bing Zhang \& H.S.Kung. Our data failed to recover the monophyly of the section although both species are resolved as members of the MCSCHMANS clade (Fig. 1b). Fraser-Jenkins [38] placed $P$. grandifrons C.Chr. in P. sect. Macropolystichum, which is not supported by our data. Given our limited phylogenetic sampling and the low support values, the taxonomic rearrangements in $P$. sect. Neopolystichum need further investigations. 17 Polystichum sect. Sorolepidium (Christ) Tagawa (Fig. 1b: clade R). - Sorolepidium Christ was often recognized as a genus (e.g., $[52,58])$. Liu et al. [59] found it being nested within Polystichum based on rbcL data. Zhang and Barrington [18] recognized it as a section of Polystichum and redefined it as being comparable to P. ser. Moupinensia H.S.Kung \& Li Bing Zhang, only a part of $P$. sect. Lasiopolystichum sensu Kung and Zhang [60]. Eight accessions representing ca. seven species are included in our study. The section is resolved as paraphyletic in relation to $P$. nudisorum Ching (a member of $P$. sect. Hypopeltis) and P. sect. Stenopolystichum (see below). Our data suggest that it might be necessary to recognize $P$. sect. Sorolepidium sensu stricto (P. duthiei (C.Hope) C.Chr. and P. glaciale Christ; Fig. 1b: clade R1; MLBS: 100 \%; MPJK: 100 \%; BIPP: 1.00) and P. sect. Lasiopolystichum Daigobo (Fig. 1b: clade R2; MLBS: 78 \%; MPJK: 77 \%; BIPP: 1.0).

Polystichum sect. Sorolepidium sensu FraserJenkins [38] also included the diploid sexual $P$. bakerianum (Atk. ex C.B. Clarke) Diels and the tetraploid sexual $P$. wilsonii Christ which were included in P. sect. Hypopeltis sensu Zhang and Barrington [18]. Our study clearly placed $P$. wilsonii as a member of clade $\mathrm{X} 1$ and the phylogenetic position of $P$. bakerianum is not resolved (Fig. 1b).

18 Polystichum sect. Hecatoptera (L.L.Xiang) Li Bing Zhang (Fig. 1b: clade S). - This monospecific section contains P. hecatopterum Diels only [18], a diploid sexual [61], and our study is the first to include this species in a molecular analysis. We could not amplify its $r b c L$ gene. Our data from other four plastid loci show that this species is definitely a member of $P$. subg. Polystichum confirming our earlier hypothesis [18], in spite of its striking morphological similarities with members of $P$. subg. Haplopolystichum in once-pinnate lamina without bulbils on its rachis [18]. Xiang [62] established $P$. ser. Hecatoptera L.L.Xiang based on its long-spinulose pinna margins but placed it in $P$. sect. Haplopolystichum, as Tagawa [36] did. Interestingly, Daigobo [37] placed this species in P. sect. Stenophyllum, which is a section of $P$. subg. Polystichum (see our discussion below) although he did not recognize any subgenera in the genus. Our ML and BI analyses resolved $P$. hecatopterum as sister to a clade containing $P$. sect. Stenopolystichum and part of $P$. sect. Sorolepidium (R2) with weak support.

19 Polystichum sect. Stenopolystichum Daigobo (Fig. 1b: clade T). - Tagawa [36] placed the type of the section, P. stenophyllum Christ, a diploid sexual species, in P. sect. Haplopolystichum based on its once-pinnate lamina and terminal sori on veinlets. Four accessions representing ca. three species of this section are included in our study. All species of this section have proliferous bulbils at the apex of lamina [18, 37]. Our study is the first to confirm the monophyly of the section. This section is resolved as monophyletic (MLBS: 75 \%; MPJK: 59 \%; BIPP: 0.99) and sister to $P$. sect. Lasiopolystichum sensu Daigobo [37] with high support values (MLBS: $97 \%$; MPJK: $94 \%$; BIPP: 1.00). This sister relationship is unexpected given the huge differences between the two sections. Polystichum sect. Lasiopolystichum was merged with $P$. sect. Sorolepidium by Zhang and Barrington [18].

20 Polystichum sect. Crinigera Li Bing Zhang (Fig. 1b: clade U). - This monospecific section contains P. crinigerum (C.Chr.) Ching only [18] and our study is the first to include it in a molecular analysis. P. crinigerum, together with $P$. nepalense and $P$. chingiae Ching, was included in $P$. sect. Polystichum by Kung et al. [4]. Our study shows that P. crinigerum is not closely related to either of them suggesting that the similarity among them in once-pinnate lamina and asymmetrical pinna base is not a synapomorphy. However, the relationships of $P$. crinigerum are not well resolved with our data. Our ML and MP analyses resolved it as sister (MLBS: 53 \%; MPJK: $51 \%$ ) to a species of $P$. sect. Hypopeltis and they together are sister (MLBS $<50 \%$ ) to P. longispinosum Ching ex Li Bing Zhang \& H.S.Kung, a species 
assigned to $P$. sect. Neopolystichum $[18,57]$. Our BI analysis resolved it as sister to P. longispinosum (BIPP: 0.73).

21 Polystichum sect. Fimbriata Li Bing Zhang (Fig. 1: clade V). - This monospecific section contains P. fimbriatum Christ [18] and our study is the first to include it in a molecular analysis. Polystichum fimbriatum is strongly (MLBS: $88 \%$; MPJK: 82 \%) supported as sister to a clade containing portions of $P$. sect. Hypopeltis (Fig. 1b: $\mathrm{X} 1$ ) in our sampling (see below). This sister relationship is unexpected given their dissimilarity in morphology of lamina shape and scales [18]. This resolution collapsed in BI analysis which resolved it as part of a trichotomy.

22 Polystichum sect. Subfimbriata Li Bing Zhang (Fig. 1b: clade W). - This monospecific section contains P. subfimbriatum W.M.Chu \& Z.R.He [18] and our study is the first to include it in a molecular analysis. When P. subfimbriatum was described, Chu and He [63] compared it with $P$. fimbriatum. Indeed, both species share once-pinnate and leathery lamina, but their scales on rachis and stipes are very different. A close relationship between these two species is not suggested with our analyses which resolved $P$. subfimbriatum as sister to portion of $P$. sect. Hypopeltis (Fig. 1b: X3; MLBS: < 50 \%; BIPP: 0.57 ) but with low statistical support.

23 Polystichum sect. Hypolepis (Michx.) T.Moore (Fig. 1b: clade X). - Zhang and Barrington [18] re-defined this section and made it the most accommodating section in the genus. They noted that this section in their definition is possibly polyphyletic. We included 55 accessions in our study. Our results show that $P$. sect. Hypolepis is indeed polyphyletic. Accessions of this section are resolved in about nine subclades, which partially corresponds to the morphological heterogeneity noticed in this section. Although polyphyletic, the majority of species belonging to P. sect. Hypolepis are included in the HYSUFI clade which also contains P. fimbriatum and P. subfimbriatum. Within this clade, three relatively well-supported subclades can be identified: the $P$. ovatopaleaceum subclade (Fig. 1b: subclade X2), the P. polyblepharum subclade (Fig. 1b: subclade X3), and the $P$. sinensis subclade (Fig. 1b: subclade X1). The $P$. polyblepharum subclade is strongly supported as monophyletic (MLBS: 99 \%; MPJK: 96 \%; BIPP: 1.00; subclade X3) and contains species from Japan (e.g., Polystichum igaense Tagawa), Taiwan (e.g., Polystichum sozanense Ching ex H. S. Kung \& Li Bing Zhang) and eastern China (e.g.,
Polystichum polyblepharum (Roemer ex Kunze) C.Presl). The P. ovatopaleaceum subclade is also supported as monophyletic (MLBS: $72 \%$; MPJK: 77 \%; BIPP: 1.00; subclade X2) and contains species from East China (e.g., Polystichum ovatopaleaceum (Kodama) Sa. Kurata), Japan (e.g., Polystichum pseudomakinoi Tagawa), and the Mascarenes (e.g., Polystichum ammifolium (Poir.) C.Chr.). The P. sinensis subclade (MLBS: 89 \%; MPJK: 73 \%; BIPP: < 0.5; subclade X1) contains species from Africa, China (especially West China), Hawaii, Japan, and the Mascarenes. Species of the $P$. sinensis subclade is also characterized by their lanceolate rachis scales. Uncertainties still remain regarding the phylogenetic positions of several species previously assigned to $P$. sect. Hypopeltis, i.e., $P$. bakerianum (Atkins.) Diels, P. braunii (Spenn.) Fée, $P$. discretum (Don) J.Sm., P. microchlamys (Christ) Kodama, P. retrosopaleaceum (Kodama) Tagawa, P. setiferum (Forssk.) Moore ex Woynar (type of the section), P. weimingii Li Bing Zhang \& H.He, members of the Australasian clade [40], and members of the Afra clade [44]. But these issues do not affect our overall topology. The monophyly of P. sect. Achroloma, P. sect. Macropolystichum, P. sect. Polystichum, $P$. sect. Sorolepidium, P. sect. Stenopolystichum, and P. sect. Xiphopolystichum is strongly supported by our analyses (Fig. 1b). Notably, the isolated positions of these species is in line with their peculiar morphology.

Polystichum discretum (diploid) and P. weimingii were placed in $P$. ser. Linearia H.S.Kung \& Li Bing Zhang based on their linear stipe scales by Zhang and Kung [64] and Zhang and Barrington [18], and our current study resolved them as sister to each other with strong support (MLBS: 100 \%; MPJK: 100 \%; BIPP: 1.00), confirming their close relationships with each other hypothesized by Zhang and He [7]. Polystichum bakerianum (diploid) and P. microchlamys (diploid or triploid) do not seem to have close relatives judging from their morphologies. A close relative of P. braunii (tetraploid), P. ningshenense Ching \& Y.P.Hsu, as hypothesized by Zhang and Kung [64], is not sampled in our current study. Zhang and Kung [64] established P. ser. Brauniana H.S.Kung \& Li Bing Zhang to accommodate $P$. braunii, $P$. ningshenense, and some species in our subclades X2 and X3 (Fig. 1b). Our current study did not recover the monophyly of $P$. ser. Brauniana.

24 The Afra, the North American, and the Australasian lineages (Fig. 1b: Afra clade, the North American clade, and the Australasian 
clade). - In our topology, several African species are grouped together in a clade with moderate support (MLBS: 65 \%; MPJK: 54 \%; BIPP: 0.90). This group was previously circumscribed and named the Afra clade by Driscoll and Barrington [44]. Unfortunately, our data do not well resolve the relationships of this lineage within Polystichum. Indeed, in the ML topology, the Afra clade is grouped together with a clade containing only species restricted to Australasia but this sister relationship is not supported by our analyses (MLBS: < 50 \%; MP: unresolved; BI: unresolved). The Australasian group (MLBS: < 50 \%; MP: unresolved; BI: unresolved) previously identified by Perrie et al. [40] and Li et al. [65] is not supported by our expanded dataset. Four accessions representing three species from North America constitute a well-supported group, consistent with the allozymic evidence by Soltis et al. [66] who found close relationships between two species of this clade [P. imbricans (D.C. Eaton) D.H. Wagner and P. munitum (Kaulf.) C.Presl]. American and African clades may deserve a taxonomic recognition as sections of P. subg. Polystichum. However, our limited taxonomic sampling clearly needs to be expanded and the relationships better resolved to unambiguously assess the monophyly and determine their relationships within the phylogeny of Polystichum.

\section{Conclusions}

Our study based on the largest character sampling and most taxonomically comprehensive sampling so far successfully resolved the 164 accessions representing ca. 140 species of Polystichum into two well-supported major clades, corresponding to the two subgenera, $P$. subg. Polystichum and P. subg. Haplopolystichum. Although our study is still preliminary of many results, given that the taxon and character sampling still needs improvements and that some results are poorly supported, our current work is the first toward a new classification based on morphological and molecular evidence in the genus Polystichum. Of the 23 sections of Polystichum recognized in a recent classification of the genus, except three monospecific sections which are each represented by one accession, four sections ( $P$. sect. Hypopeltis, $P$. sect. Neopolystichum, P. sect. Sorolepidium, P. sect. Sphaenopolystichum) are resolved as paraphyletic or polyphyletic, 16 are recovered as monophyletic. Of the 16 monophyletic sections, two ( $P$. sect. Adenolepia, $P$. sect. Cyrtogonellum) are weakly supported and 14 are strongly supported. In addition, our study also recovered the monophyly of the Afra clade (moderately supported) and the North American clade (strongly supported). The relationships of 11 sections (5 in $P$. subg. Haplopolystichum; 6 in $P$. subg. Polystichum) are well resolved (MLBS $\geq 78 \%$; MPJK $\geq 76 \%$ ). However, several phylogenetic uncertainties remain, particularly in $P$. sect Hypopeltis. These issues probably linked to introgression and/or fast radiation highlight the fact that more data including nuclear data are needed to obtain a complete picture of the evolutionary relationships in polystichoid ferns and therefore draw a new taxonomic framework for one of the largest genera of ferns, Polystichum.

\section{Methods}

Taxonomic sampling

To test the monophyly of the two subgenera and $23 \mathrm{sec}-$ tions recognized in the most recent classification of Polystichum [18], we included 121 accessions representing about 106 species of $P$. subg. Polystichum and 43 accessions representing 34 species of $P$. subg. Haplopolystichum (see Table 1). Specifically, we sampled at least one species for each of the 23 sections including the monospecific sections $P$. sect. Chingiarum Li Bing Zhang, P. sect. Crinigera Li Bing Zhang, P. sect. Fimbriata Li Bing Zhang, P. sect. Hecatoptera (L.L.Xiang) Li Bing Zhang, and P. sect. Subfimbriata Li Bing Zhang. The bitypic $P$. sect. Mastigopteris Tagawa is represented by one species, and all other non-monospecific sections by 2 to 46 species. In detail, $P$. sect. Achroloma Tagawa was represented by two species, $P$. sect. Adenolepia Daigobo by four species, $P$. sect. Basigemmifera (W.M.Chu \& Z.R.He) Li Bing Zhang by three species, $P$. sect. Crucifilix Tagawa by three species, $P$. sect. Cyrtomiopsis Tagawa by two species, $P$. sect. Cyrtogonellum (Ching) Li Bing Zhang by three species, P. sect. Haplopolystichum Tagawa by six species, $P$. sect. Hypopeltis (Michx.) T.Moore by 46 species, P. sect. Macropolystichum Daigobo by eight species, $P$. sect. Micropolystichum Tagawa by two species, $P$. sect. Neopolystichum Ching ex Li Bing Zhang \& H.S.Kung by two species, $P$. sect. Platylepia Li Bing Zhang by three species, P. sect. Polystichum by nine species, $P$. sect. Sorolepidium (Christ) Tagawa by seven species, P. sect. Sphaenopolystichum Ching ex W.M.Chu \& Z.R.He by five species, $P$. sect. Stenopolystichum Daigobo by two species, and $P$. sect. Xiphopolystichum Daigobo by 14 species. To make our study more taxonomically meaningful, we sampled the type species of all supraspecific taxa recognized by Zhang and Barrington [18]. Our overall sampling represents almost all major diversity centers of Polystichum except the Indonesian-Papuan region. The detailed sampling sites are listed in the Additional file 1. Field work permissions were not required for all the sampling sites except Réunion for which the permission was issued by the National Park of Réunion. 
Given that Cyrtomium (sensu [18]) and Phanerophlebia are both monophyletic [42, 43, 51, 67] and each mainly distributed in only one area (i.e., East Asia and southwestern U.S.A. to Central America, respectively), we included six species of Cyrtomium and two of Phanerophlebia. Denser sampling of these two genera will be performed in a separate ongoing study (Le Péchon et al., unpubl. data). Based on previous molecular [1, 41, 42, 44, 49, 59, 68-70] and morphological works [71], five species of Dryopteris Adans. and two of Arachniodes Blume were included as outgroups. In total, 177 accessions representing ca. 153 species in the subfamily Dryopterioideae (sensu [71]) were included in this study. Taxa included, their classification, voucher information, and GenBank accession numbers are given in Additional file 1.

\section{DNA extraction, PCR amplification and sequencing}

Genomic DNA was extracted from fresh, silica-gel dried, or herbarium leaf fragments using TIANGEN plant genomic DNA extraction kit (TIANGEN Biotech., Beijing, China) according to the manufacturer's protocols. We selected five chloroplast regions (the intergenic spacers psbA-trnH, trnS-rps 4 and trnL-trnF, the trnL intron, and the protein-coding gene $r b c L$ ). The primers used to amplify these regions were based on previous studies or newly designed (Table 3 ). The PCR protocols followed Zhang et al. [72] and Small et al. [73]. All regions were amplified in $25 \mu \mathrm{L}$ volumes, with $15.85 \mu \mathrm{L}$ deionized sterile water, $2.5 \mu \mathrm{L}$ of $25 \mathrm{~mol} / \mathrm{L}$ EasyTaq Buffer, $1.5 \mathrm{~mL}$ of $25 \mathrm{mmol} / \mathrm{L} \mathrm{MgCl}_{2}$ solution, $2 \mu \mathrm{L}$ of a $2.5 \mathrm{mmol} / \mathrm{L}$ dNTP solution in equimolar ratio, $1 \mu \mathrm{L}$ of each primer at $10 \mathrm{pmol} / \mu \mathrm{L}, 1$ unit $(0.2 \mu \mathrm{L})$ of EasyTaq DNA polymerase (TransGen Biotech, Beijing, China), and $1 \mu \mathrm{L}$ of

Table 3 Selected molecular markers and their primers used in this study

\begin{tabular}{llll}
\hline $\begin{array}{llll}\text { Molecular } \\
\text { marker }\end{array}$ & $\begin{array}{l}\text { Primer } \\
\text { name }\end{array}$ & Sequence $(5 \rightarrow 3)$ & References \\
\hline psbA-trnH & psbA & GTT ATG CAT GAA CGT AAT GCT C & {$[85]$} \\
& trnH & CGC GCA TGG TGG ATT CAC AAT CC & {$[86]$} \\
rbcL & rbcL-1F & ATGTCACCACAAACAGAAACTAAAGC & {$[87]$} \\
& rbcL- & AAT TCY CAR CCR TTC ATG CGT & This study \\
& $595 F$ & & \\
& rbcL- & AGC TAA GCT GGT RTT KGC RGT & This study \\
& $895 R$ & & \\
& rbcL- & TCACAAGCAGCAGCTAGTTCAGGACTC & {$[88]$} \\
rps4-trns & trnS & ATG AAT T(A/G)T TA G TTG TTG AG & {$[89]$} \\
& rps4 & TAC CGA GGG TTC GAA TC & {$[90]$} \\
trnL-trnL- & fern1 & GGCAGCCCCCARATTCAGGGRAACC & {$[91]$} \\
& & & {$[92]$} \\
\hline
\end{tabular}

the template DNA. PCR products were purified and sequenced by Invitrogen (Shanghai, China).

\section{Sequence alignment and phylogenetic reconstruction}

The resulting sequences were edited and assembled with Sequencher V.4.14 (GeneCodes Corporation, Ann Arbor, Michigan, USA). We manually performed the sequence alignment using Bioedit [74]. Gaps (insertion/deletion events) were considered as missing data. Phylogenetic relationships were reconstructed using maximum parsimony (MP), maximum likelihood (ML), and Bayesian inference (BI). Maximum parsimony jackknife (MPJK) analyses [75] were conducted using PAUP* for each dataset with the removal probability set to approximately $37 \%$; and "jac" resampling emulated. One thousand replicates were performed, each from a different random addition sequence tree, with 100 TBR searches per replicate and a maximum of 100 trees held per TBR search. A final simultaneous MP analysis [76, 77] was conducted based on the combined dataset including the five molecular markers.

Each DNA region of the concatenated molecular matrix was assigned a separate $\mathrm{GTR}+\mathrm{I}+\mathrm{G}$ substitution model. ML tree searches and 10,000 rapid bootstrapping (MLBS) were conducted using RAxML-HPC and default parameters, followed by a search for the best-scoring tree, in a single run $[78,79]$.

jModelTest 2 [80] was used to select the best-fit likelihood model for Bayesian analyses. The Akaike information criterion [81] was used to select among models. The models selected were GTR+G (psb-trnH spacer), GTR+I+G (rps4-trnS spacer, the combined region trnL$\operatorname{trn} F$ and $r b c L$ gene). The selected models (Table 2) were then used for tree searches from the respective data partitions in combination. BI analyses were performed using MrBayes v3 [82]. For each DNA partition, we used the appropriate model selected by jModelTest 2 , and each molecular region has independent parameters and the overall rate is allowed to be different across partitions. Four chains (i.e., three heated and one cold) of Metropolis-coupled Markov chain Monte Carlo were performed for 50 million generations, sampling every 1000th generation. After checking the convergence of parameter traces among generations using Tracer [83], we discarded the first $25 \%$ of sampled trees as a "burnin phase". The remaining trees were then used to calculate Bayesian inference posterior probability (BIPP).

$\mathrm{ML}$ and BI analyses were run on the CIPRES cluster available at http://www.phylo.org/ [84].

\section{Availability of supporting data}

DNA sequence alignments and tree are available in the TreeBase (https://treebase.org/treebase-web/search/study/ 
summary.html?id=18607). Taxa sampled with information related to taxonomy, voucher information, and GenBank accession numbers are available in Additional file 1.

\section{Additional file}

Additional file 1: List of taxa sampled with information related to taxonomy, voucher information, GenBank accession numbers. * denotes when only the intergenic spacer $\operatorname{trn} L-\operatorname{trnF}$ is available. Na: data not available. (DOC $96 \mathrm{~kb}$ )

\section{Abbreviations}

BI: bayesian inferences; BIPP: bayesian inference posterior probabilities; HYMASO: clade including the sections Hypopeltis-MacropolystichumSorolepidium; HYSUFI: clade including the sections Hypopeltis-SubfimbriataFimbriata; MCSCHMANS: clade including the sections, MacropolystichumChingiarum-Sorolepidium-Crinigera-Hecatoptera-Micropolystichum-AchrolomaNeopolystichum-Stenopolystichum; ML: maximum likelihood; MLBS: maximum likelihood bootstrap; MP: maximum parsimony; MPJK: maximum parsimony jackkniffe.

\section{Competing interests}

The authors declare that they have no competing interests.

\section{Authors' contributions}

TLP and LBZ designed the study, conducted data analyses, and wrote the manuscript, TLP carried out the lab work, TLP, HH, LZ, XMZ, XFG, and LBZ helped with portion of the fieldwork. All authors contributed to the manuscript revision. All authors read and approved the final manuscript.

\section{Acknowledgments}

The research was partially supported by a grant from Chengdu Institute of Biology, Chinese Academy of Sciences (CAS) and grants from the National Geographical Society of the USA to L.-B.Z., a CAS Research Fellowship for International Young Researchers (\#31150110463) and support from the Claude Leon Foundation to T.L.P., and a National Natural Science Foundation of China each to H.H. (\#31370534) and to L.Z. (\#31400196), a grant from the Fondation Franklinia to the Flora of China project, and the CAS/SAFEA International Partnership Program for Creative Research Teams. We are grateful to the National Park of Réunion for collecting permission in Réunion. We thank Wei-Ming Chu, Holly Forbes, Zhao-Rong He, Jacobus P. Roux, PeiShan Wang, Zhangming Zhu, the Royal Botanical Garden Edinburgh, NOl, CBNM, and the University of California Botanical Garden at Berkeley, for help with collecting DNA samples, Leon Perrie for unpublished sequences, and two anonymous reviewers for helpful comments.

\section{Author details}

${ }^{1}$ Chengdu Institute of Biology, Chinese Academy of Sciences, P.O. Box 416, Chengdu, Sichuan 610041, China. ${ }^{2}$ School of Life Sciences, University of KwaZulu-Natal, Private Bag X01 Scottsville, Pietermaritzburg 3209, South Africa. ${ }^{3}$ School of Life Sciences, Chongqing Normal University, Shapingba, Chongqing 400047, China. ${ }^{4}$ School of Life Sciences, Sichuan University, Chengdu, Sichuan 610064, China. ${ }^{5}$ Missouri Botanical Garden, P.O. Box 299, St. Louis, MO 63166-0299, USA.

Received: 15 September 2015 Accepted: 23 February 2016 Published online: 29 February 2016

\section{References}

1. Little DP, Barrington DS. Major evolutionary events in the origin and diversification of the fern genus Polystichum (Dryopteridaceae). Amer J Bot. 2003;90:508-14.

2. Fraser-Jenkins CR. An outline monographic study of the genus Polystichum in the Indian subcontinent. In: Bhardwaj TN, Gena CB, editors. Aspects of Plant Science. New Delhi: Today \& Tomorrows Printers \& Publishers; 1991. p. 249-87.

3. Barrington DS. Polystichum. In: Moran RC, Riba R, editors. Flora Mesomaricana. Vol. 1. Psilotaceae a Salviniaceae. México: Universidad Nacional Autonoma de México; 1995. p. 218-25.
4. Kung H-S, Chu W-M, He Z-R, Zhang L-B. Polystichum. In: Wu C-Y, editor. Flora of Reipublicae Popularis Sinicae. Vol. 5. Beijing: Science Press; 2001. p. 1-246.

5. Barrington DS. A world-level phylogenetic and biogeographic perspective on the fern genus Polystichum. In Abstract presented at Botany. Boise, Utah; 2014: http://2014.botanyconference.org/engine/search/index. php?func $=$ detail\&aid $=291$.

6. Zhang L-B, He H. Polystichum minutissimum sp. nov. (sect. Haplopolystichum, Dryopteridaceae): The smallest Polystichum found in a karst cave in China. Bot Stud. 2009;50:353-8.

7. Zhang L-B, He H. Polystichum weimingii sp. nov. (sect. Metapolystichum, Dryopteridaceae) from Southern Yunnan, China. Syst Bot. 2009;34:13-6.

8. Zhang L-B, He H. Polystichum peishanii (sect. Haplopolystichum, Dryopteridaceae): A new fern species from a limestone area in Guizhou, China. Bot Stud. 2009;50:101-6.

9. Zhang L-B, He H. Polystichum speluncicola sp. nov. (sect. Haplopolystichum Dryopteridaceae) Based on morphological, palynological, and molecular evidence with reference to the non-monophyly of Cyrtogonellum. Syst Bot. 2010;35:13-9.

10. Zhang L-B, He H. Polystichum fengshanense, sp. nov. (sect. Haplopolystichum, Dryopteridaceae) from karst caves in Guangxi, China based on morphological, palynological, and molecular evidence. Syst Bot. 2011;36:854-61.

11. Zhang L-B, He H. Polystichum perpusillum (sect. Haplopolystichum, Dryoptericeae), a new fern species from Guizhou, China. Ann Bot Fenn. 2012;49:67-74.

12. He H, Zhang L-B. Polystichum kungianum, sp. nov. (sect. Mastigopteris, Dryopteridaceae) from Chongqing, China. Bot Stud. 2010;51:395-401.

13. He H, Zhang L-B. Polystichum cavernicola, sp. nov. (sect. Haplopolystichum, Dryopteridaceae) from a karst cave in Guizhou, China and its phylogenetic affinitie. Bot Stud. 2011;52:121-7.

14. He H, Zhang L-B. Polystichum oblanceolatum, a new species in section Haplopolystichum (Dryopteridaceae) from Guangxi, China. Novon. 2012:22:160-5.

15. Zhang L-B, He H, Luo Q. Polystichum puteicola, sp. nov. (sect. Haplopolystichum, Dryopteridaceae) from a karst sinkhole in Guizhou, China based on molecular, palynological, and morphological evidence. Bot Stud. 2010;51:127-36.

16. He H, Yang Y-Q, Zhang L-B. Polystichum loratum (Dryopteridaceae), a new fern species from Guizhou, China. Novon. 2012;22:166-9.

17. Luo Q, Zhang L-B. Polystichum tiankengicola (Dryopteridaceae), a new species from a karst sinkhole from Guizhou, China. Novon. 2012:22:186-90.

18. Zhang L-B, Barrington DS. Polystichum. In: Wu Z-Y, Raven PH, Hong D-Y, editors. Flora of China. Vol. 2-3 (Pteridophytes). St. Louis: Missouri Botanical Garden Press; Science Press; 2013. p. 629-713.

19. Lu NTHI, Zhang L, Zhang L-B. Polystichum hagiangense (subg. Haplopolystichum; Dryopteridaceae), a new fern species from Ha Giang Province, Northern Vietnam. Phytotaxa. 2014;175:293-7.

20. Zhang L-B. Taxonomic and nomenclatural notes on the fern genus Polystichum (Dryopteridaceae) in China. Phytotaxa. 2012;60:57-60.

21. Lin Y-X, Viane R. Aspleniaceae. In: Wu ZL, Raven PH, Hong DY, editors. Flora of China, Vol. 2-3 (Pteridophytes). Volume 2. Beijing: Science Press; St Louis: Missouri Botanical Garden Press; 2013. p. 267-316.

22. Skog JE, Mickel J, Moran RC, Volovsek M, Zimmer EA. Molecular studies of representative species in the fern genus Elaphoglossum (Dryopteridaceae) based on cpDNA sequences rbcL, trnL-F, and rps4-trnS. Int J Plant Sci. 2004;165:1063-75.

23. Iwatsuki K. Dryopteridaceae. In: Iwatsuki K, Yamazaki T, Boufford DE, Ohba H, editors. Flora of Japan, Vol. 1. Tokyo: Kodansha; 1995. p. 120-73.

24. Kessler M, Smith A, Sundue M. Notes on the genus Polystichum (Dryopteridaceae) in Bolivia, with descriptions of ten new species. Brittonia. 2005;57:205-27

25. Barrington DS. The fern genus Polystichum (Dryopteridaceae) in Costa Rica. Ann Missouri Bot Gard. 2012;98:431-46.

26. Mickel JT, Smith AR. The Pteridophytes of Mexico. Mem N Y Bot Gard. 2004:88:1-1054.

27. Mickel JT. A review of the West Indian species of Polystichum. In: Johns RJ, editor. Holttum Memorial Volume. Surrey: Royal Botanic Gardens, Kew; 1997. p. 119-43.

28. Wagner DH. Polystichum, Phanerophlebia. In: Editorial Committee, editor. Flora of North America North of Mexico. New York: Oxford University Press; 1993. 
29. Roux J. The genus Polystichum (Dryopteridaceae) in Africa. Bull Nat Hist Mus London Bot. 2000;30:33-79.

30. Roux JP. A review of the fern genus Polystichum (Pteropsida: Dryopteridaceae) in Madagascar and the Mascarene region. Adansonia. 2001;23:265-87.

31. Roux JP. The fern genus Polystichum (Pteropsida: Dryopteridaceae) in Macaronesia. Syst Biodivers. 2004;2:147-61.

32. Tutin TG, Burges NA, Chater AO, Edmonson JR, Heywood VH, Moore DH, et al. Flora Europaea, Vol. 1. Cambridge: Cambridge University Press; 1993.

33. Brownsey PJ, Smith-Dodsworth JC. New Zealand Ferns and Allied Plants. 2nd ed. Auckland: David Bateman Ltd; 2000.

34. Green PS. Dryopteridaceae. Flora Aust. 1994;49:603-4.

35. Keyserling AFM. Polypodiacea et Cyatheacea Herbarii Bungeani. Leipzig: Engelmann; 1873.

36. Tagawa M. Polystichum of Japan, Korea, and Formosa I. Acta Phytotax Geobot. 1940;9:119-38.

37. Daigobo S. Taxonomical studies on the fern genus Polystichum in Japan, Ryukyu, and Taiwan. Sci Reports Tokyo Kyoiku Daigaku Sect B Zool Bot. 1972:15:57-80

38. Fraser-Jenkins CR. New Species Syndrome in Indian Pteridology and the Ferns of Nepal. Dehra Dun: International Book Distributors; 1997.

39. Roux JP. A taxonomic revision of Polystichum (Pteropsida: Dryopteridaceae) in Africa and neighbouring islands. In: Dissertation. Pretoria: University of Pretoria; 1998.

40. Perrie LR, Brownsey PJ, Lockhart PJ, Brown EA, Large MF. Biogeography of temperate Australasian Polystichum ferns as inferred from chloroplast sequence and AFLP. J Biogeogr. 2003;30:1729-36.

41. Li C-X, Lu S-G, Yang Q. Asian origin for Polystichum (Dryopteridaceae) based on rbcL sequences. Chinese Sci Bull. 2004;49:1146.

42. Li C-X, Lu S-G, Barrington DS. Phylogeny of Chinese Polystichum (Dryopteridaceae) based on chloroplast DNA sequence data (trnL-F and rps4-trnS). J Plant Res. 2008;121:19-26.

43. Lu J-M, Li D-Z, Gao L-M, Cheng X, Wu D. Paraphyly of Cyrtomium (Dryopteridaceae): evidence from $r b c L$ and $t r n L-F$ sequence data. J Plant Res. 2005:118:129-35.

44. Driscoll HE, Barrington DS. Origin of Hawaiian Polystichum (Dryopteridaceae) in the context of a world phylogeny. Am J Bot. 2007;94:1413-24.

45. McHenry MA, Barrington DS. Phylogeny and biogeography of exindusiate Andean Polystichum (Dryopteridaceae). Am J Bot. 2014;101:365-75.

46. Mason-Gamer RJ, Kellog EA. Testing for phylogenetic conflict among molecular data sets in the tribe Triticeae (Gramineae). Syst Biol. 1996:45:524-45.

47. Zhang L-B, Simmons MP. Phylogeny and delimitation of the Celastrales inferred from nuclear and plastid genes. Syst Bot. 2006;31:122-37.

48. Zhou X-M, Rothfels CJ, Zhang L, He Z-R, Le Péchon T, He H, Lu NT, Knapp S, Lorence DH, He X-J, Gao X-F, Zhang L-B. A large-scale phylogeny of the lycophyte genus Selaginella (Selaginellaceae: Lycopodiopsida) based on plastid and nuclear loci. Cladistics. 2015; doi: 10.1111/cla.12136.

49. Lu J-M, Barrington DS, Li D-Z. Molecular phylogeny of the polystichoid Ferns in Asia based on rbcL sequences. Syst Bot. 2007;32:26-33.

50. Mckeown M, Sundue M, Barrington D. Phylogenetic analyses place the Australian monotypic Revwattsia in Dryopteris (Dryopteridaceae). PhytoKeys. 2012;14:43-56

51. Yatskievych G, Stein DB, Gastony GJ. Chloroplast DNA evolution and systematics of Phanerophlebia (Dryopteridaceae) and related fern genera. Proc Natl Acad Sci. 1988;85:2589-93.

52. Hsieh Y-T. Cyrtogonellum, Sorolepidium, Cyrtomidyctum. In: Kung H-S, editor. Wu C-Y (ed.), Flora Reipublicae Popularis Sinicae, vol. 5. Beijing: Science Press; 2001. p. 177-82. 217-222.

53. Liu H-M, Zhang X-C, Wang W, Zeng H. Molecular phylogeny of the endemic fern genera Cyrtomidictyum and Cyrtogonellum (Dryopteridaceae) from East Asia. Org Divers Evol. 2010;10:57-68.

54. Zhang L-B, Wang P-S. Polystichum normale (Dryopteridaceae), a new species in section Crucifilix from Guizhou, China. Novon. 2012;22:250-5.

55. Lu NT, Zhang L, Zhang L-B. Ten new records of Polystichum (Dryopteridaceae) for Vietnam and lectotypification of Polystichum atroviridissimum and P. fimbriatum. Phytotaxa. 2014;164:115-23.

56. Zhang L-B, Kung H-S. Taxonomic study on the fern genus Polystichum sect. Metapolystichum Tagawa from China (I). Acta Phytotaxon Sin. 1995;33:469-75.

57. Zhang L-B, Kung H-S. A new section of the fern genus Polystichum Roth - sect. Neopolystichum Ching. Acta Phytotaxon Sin. 1999;37:81-6.

58. Ching R-C. The Chinese fern families and genera: systematic arrangement and historical origin. Acta Phytotaxon Sin. 1978;16:1-19.
59. Liu H-M, Zhang X-C, Chen Z-D, Qiu Y-L. Inclusion of the Eastern Asia endemic genus Sorolepidium in Polystichum (Dryopteridaceae): Evidence from the chloroplast rbcL gene and morphological characteristics. Chinese Sci Bull. 2007:52:631-8.

60. Kung H-S, Zhang L-B. Study on the fern genus Polystichum Roth sect. Lasiopolystichum Daigobo from China. Acta Phytotaxon Sin. 1998;36: 242-54

61. Wang Z-R, Zhang Z-X. Cytological observation on some Chinese Ferns. Acta Bot Sin. 1981;23:428-33.

62. Xiang L-L. A taxonomical study of the genus Polystichum Roth section Haplopolystichum Tagawa from Yunnan. Acta Phytotaxon Sin. 1994;31:258-67.

63. Chu W-M, He Z-R. Taxonomic notes on some pteridophytes from Yunnan (mainly Dulongjiang and neigbouring regions). Acta Bot Yunnanica. 2000;22:255-62.

64. Zhang L-B, Kung H-S. Taxonomic study on the fern genus Polystichum sect. Metapolystichum Tagawa from China (I). Acta Phytotaxon Sin. 1996:34:68-76

65. Li C-X, Lu S-G, Yang Q. Phylogeny and biogeography of Chinese and Australasian Polystichum ferns as inferred from chloroplast trnL-F and rps4trnS sequence data. Palaeoworld. 2007;16:294-300.

66. Soltis PS, Soltis DE, Wolf PG. Allozymic divergence in North American Polystichum (Dryopteridaceae). Syst Bot. 1990;15:205-15.

67. Yatskievych G. A revision of the fern genus Phanerophlebia (Dryopteridaceae). Ann Missouri Bot Gard. 1996;83:168-99.

68. Schuettpelz E, Pryer K. Fern phylogeny inferred from 400 leptosporangiate species and three plastid genes. Taxon. 2007;56(November):1037-50.

69. Zhang L-B, Zhang L. The inclusion of Acrophorus, Diacalpe, Nothoperanema, and Peranema in Dryopteris: The molecular phylogeny, systematics, and nomenclature of Dryopteris subg. Nothoperanema (Dryopteridaceae). Taxon. 2012:61:1199-216.

70. Zhang L-B, Zhang L, Dong S-Y, Sessa EB, Gao X-F, Ebihara A. Molecular circumscription and major evolutionary lineages of the fern genus Dryopteris (Dryopteridaceae). BMC Evol Biol. 2012;12:180.

71. Zhang L-B, Barrington DS, Iwatsuki K, Christenhusz MJM, Mickel JT, Kato M, et al. Dryopteridaceae. In: Wu ZL, Raven PH, Hong DY, editors. Wu C-Y, Raven PH, Hong D-Y (eds.), Flora of China, Vol. 2-3 (Pteridophytes). Beijing: Science Press; St Louis: Missouri Botanical Garden Press; 2013. p. 541-724.

72. Zhang L, Rothfels CJ, Ebihara A, Schuettpelz E, Le Péchon T, Kamau P, et al. A global plastid phylogeny of the brake fern genus Pteris (Pteridaceae) and related genera in the Pteridoideae. Cladistics. 2015;31:406-23.

73. Small RL, Lickey EB, Shaw J, Hauk WD. Amplification of noncoding chloroplast DNA for phylogenetic studies in lycophytes and monilophytes with a comparative example of relative phylogenetic utility from Ophioglossaceae. Molec Phylogenet Evol. 2005;36:509-22.

74. Hall T. BioEdit: a user-friendly biological sequence alignment editor and analysis program for Windows 95/98/NT. Nucleic Acids Symp Ser. 1999;41:95-8.

75. Farris JS, Albert VA, Källersjö M, Lipscomb D, Kluge AG. Parsimony jackknifing outperforms neighbor-joining. Cladistics. 1996;12:99-124.

76. Kluge AG. A concern for evidence and a phylogenetic hypothesis of relationships among Epicrates (Boidae, Serpentes). Syst Zool. 1989;38:7-25.

77. Nixon KC, Carpenter JM. On consensus, collapsibility, and clade concordance. Cladistics. 1996;12:305-21.

78. Stamatakis A, Hoover $\mathrm{P}$, Rougemont J. A rapid bootstrap algorithm for the RAxML Web servers. Syst Biol. 2008;57:758-71.

79. Stamatakis A. RAxML-VI-HPC: maximum likelihood-based phylogenetic analyses with thousands of taxa and mixed models. Bioinformatics. 2006; 22:2688-90.

80. Darriba D, Taboada GL, Doallo R, Posada D. jModelTest 2: more models, new heuristics and parallel computing. Nat Methods. 2012;9:772.

81. Akaike H. A new look at the statistical model identification. Autom Control IEEE Trans Autom Control. 1974;19:716-23.

82. Ronquist F, Huelsenbeck JP. MrBayes 3: Bayesian phylogenetic inference under mixed models. Bioinformatics. 2003;19:1572

83. Rambaut A, Drummond AJ. Tracer 1.4. Available at http://tree.bio.ed.ac.uk/ software/tracer. 2007.

84. Miller MA, Pfeiffer W, Schwartz T. Creating the CIPRES Science Gateway for inference of large phylogenetic trees. In: Proceedings of the Gateway Computing Environments Workshop (GCE). New York: Institute of Electrical and Electronics Engineers; 2010. p. 1-8.

85. Sang T, Crawford DJ, Stuessy TF. Chloroplast DNA phylogeny, reticulate evolution, and biogeography of Paeonia (Paeoniaceae). Am J Bot. 1997;84:1120-36. 
86. Tate JA, Simpson BB. Paraphyly of Tarasa (Malvaceae) and diverse origins of the polyploid species. Syst Bot. 2003;28:723-37.

87. Fay MF, Swensen SM, Chase MW. Taxonomic affinities of Medusagyne oppositifolia (Medusagynaceae). Kew Bull. 1997;52:111-20.

88. Wolf $\mathrm{P}$, Sipes $\mathrm{S}$, White M. Phylogenetic relationships of the enigmatic fern families Hymenophyllopsidaceae and Lophosoriaceae: evidence from rbcL nucleotide sequences. Plant Syst Evol. 1999;219:263-70.

89. Shaw J, Lickey EB, Beck JT, Farmer SB, Liu W, Miller J, et al. The tortoise and the hare II: relative utility of 21 noncoding chloroplast DNA sequences for phylogenetic analysis. Am J Bot. 2005;92:142-66.

90. Souza-Chies T, Bittar G, Nadot S, Carter L. Phylogenetic analysis of Iridaceae with parsimony and distance methods using the plastid gene rps4. Plant Syst Evol. 1997;204:109-23.

91. Trewick S, Morgan RM, Russell SJ, Henderson S, Rumsey FJ, Pintér I, et al. Polyploidy, phylogeography and Pleistocene refugia of the rockfern Asplenium ceterach: evidence from chloroplast DNA. Mol Ecol. 2002;11:2003-12.

92. Taberlet P, Gielly L, Pautou G. Universal primers for amplification of three non-coding regions of chloroplast DNA. Plant Mol Biol. 1991;17:1105-9.

Submit your next manuscript to BioMed Central and we will help you at every step:

- We accept pre-submission inquiries

- Our selector tool helps you to find the most relevant journal

- We provide round the clock customer support

- Convenient online submission

- Thorough peer review

- Inclusion in PubMed and all major indexing services

- Maximum visibility for your research

Submit your manuscript at www.biomedcentral.com/submit
Biomed Central 